\title{
ANALISIS MINAT BELAJAR SISWA PADA MATERI KPK DAN FPB MENGGUNAKAN PENDEKATAN SAINTIFIK BERBANTUAN APLIKASI VISUAL BASIC EXCEL (VBE)
}

\author{
Neng Cucu Nurmaenah ${ }^{1}$, Selvi Aginai ${ }^{2}$, Yulianda Putri $\mathbf{H}^{3}$, Siti Chotimah ${ }^{4}$ \\ 1, 2, 3,4 IKIP Siliwangi, Jl. Terusan Jendral Sudirman, Cimahi Tengah, Kota Cimahi, Jawa Barat \\ cucu.ncnm@gmail.com
}

\begin{abstract}
Abstrak
This study aims to analyze the learning interests of Class IV Elementary students in learning mathematics on the KPK and FPB material assisted by the VBA Excel application by using 20 indicators of learning interest. The research method for analysis uses descriptive qualitative method, with the instrument used in the form of giving questionnaires containing positive and negative statements to analyze students' interest in learning mathematics. The sample subject in the study was grade IV Cibungur State Primary School located in West Bandung with the number of students 29 people. The results obtained from research that students' interest in learning mathematics learning aided by VBA Excel in the KPK and FPB material is good. Keywords: Analysis of interest in learning, VBA Excel

Keywords: Analysis of interest in learning, VBA Excel

Abstrak

Penelitian ini bertujuan untuk menganalisis minat belajar siswa Kelas IV SD dalam belajar matematika pada materi KPK dan FPB berbantuan aplikasi VBA Excel dengan menggunakan 20 indikator minat belajar. Metode penelitian untuk analisis menggunakan metode kualitatif deskriptif, dengan instrumen yang digunakan berupa pemberian angket yang berisi pernyataan positif dan negatif untuk menganalisis minat belajar siswa dalam pembelajaran matematika.Subjek sampel pada penelitian adalah kelas IV Sekolah Dasar Negeri Cibungur yang berada di Bandung Barat dengan jumlah siswa 29 orang. Hasil yang didapatkan dari penelitian bahwa minat belajar siswa pada pembelajaran matematika berbantuan VBA Excel pada materi KPK dan FPB adalah baik.
\end{abstract}

Kata Kunci: Analisis minat belajar, VBA Excel

\section{PENDAHULUAN}

Matematika merupakan ilmu yang sangat penting untuk dipelajari, ditinjau dari berbagai manfaat yang diberikan untuk memudahkan kita dalam mempelajari materi pembelajaran yang lain ataupun pemanfaatan materi matematika itu sendiri dalam kehidupan sehari-hari. Contohnya ketika kita bertransaksi, menghitung data penduduk, mengukur luas tanah, mengukur volume bangun ruang, menghitung kecepatan suatu kendaraan, bahkan meneliti benda-benda yang ada di luar angkasa juga menggunakan ilmu matematika.(Ambarwati, Setiawan, Akbar, \& Afrilianto, 2018) Rendahnya pemahaman matematis, mengakibatkan timbulnya kesulitan dalam mempelajari matematika, sehingga siswa menjadi kurang berminat dalam pelajaran matematika. Oleh sebab itu pemahaman konsep matematika sangatlah penting untuk dikuasai agar mempermudah menerapkannya dalam kehidupan sehari-hari.

Pengetahuan diartikan bahwa jika seseorang yang berminat terhadap suatu pelajaran maka akan mempunyai pengetahuan yang luas tentang pelajaran tersebut serta bagaimana manfaat belajar dalam kehidupan sehari-hari (Nurhasanah \& Sobandi, 2016). Minat belajar adalah suatu ketertarikan terhadap suatu pelajaran yang kemudian mendorong individu untuk mempelajari dan menekuni pelajaran tersebut. Lingkungan yang baik dan sehat dapat mendorong siswa untuk memiliki keinginan 
dan kegairahan belajar. Selain lingkungan, keinginan dan kegairahan belajar dipengaruhi oleh kondisi siswa itu sendiri pada saat belajar, jika kondisi yang dihadapi kurang mendukung biasanya siswa akan cenderung kurang berminat untuk belajar ataupun kurang konsentrasi dalam mengikuti setiap pelajaran yang diberikan. Memacu minat belajar pada setiap pembelajaran itu penting, terlebih dalam pelaksanaan pembelajaran matematika yang bagi sebagian siswa kurang diminati. Jika siswa kurang berminat mempelajari matematika maka kemampuan siswa di bidang matematika akan terhambat.

Alternatif yang digunakan untuk meningkatkan minat belajar siswa adalah dengan menggunakan alat bantu berupa media pembelajaran Visual Basic Excel (VBE). Aplikasi VBA merupakan salah satu media pembelajaran yang bisa dibilang sesuatu yang baru bagi siswa SD pada umumnya. Sehingga ketika media tersebut digunakan dalam pembelajaran dapat menarik siswa untuk memperhatikan dan mengikuti pembelajaran dengan baik (Nurhayati \& Chotimah, 2020). Jadi alasan pemilihan alat peraga tersebut agar siswa lebih mudah memahami materi pembelajaran, karena melalui VBE dapat ditampilkan gambar-gambar dan cara cepat dalam menjawab soal matematika. Menurut Chotimah (2019) Penggunaan aplikasi sebagai media dalam pembelajaran cocok untuk pembelajaran matematika terutama materi yang memerlukan gambar, suara maupan animasi yang sangat berpengaruh pada siswa sekolah dasar dalam memahami materi yang cenderung beranjak dari hal-hal yang kongkrit.

Pendekatan saintifik adalah pendekatan pembelajaran dengan menggunakan pendekatan ilmiah dan inkuiri dimana peserta didik diarahkan dan dibimbing pada kegiatan mengobservasi, menanya, mencoba, menalar dan membangun jejaring atau mengkomunikasikan untuk menyebarluaskan hasil belajar yang diperoleh. Menurut Rostika, Indonesia, \& Cibiru, (2019) Pendekatan pembelajaran saintifik merupakan titian emas bagi perkembangan dan pengembangan sikap, keterampilan, dan pengetahuan peserta didik. Salah satu materi pembelajaran yang dipelajari di kelas IV Sekolah Dasar adalah KPK dan FPB. Materi tersebut dirasa penting untuk dipelajari karena banyak diaplikasikan dalam kehidupan sehari-hari. Contohnya untuk menghitung jumlah pembelahan bakteri dalam mata pelajaran Biologi. (Rostika et al., 2019) mengemukakan bahwa penyajian materi yang menarik, menyenangkan, sederhana, mudah dipahami, dan sesuai dengan kondisi siswa, merupakan modal utama untuk memberi rasa senang atau joy of clear terhadap matematika. Sedangkan menurut (Andiyana, Maya, \& Hidayat, 2018) siswa sering mengalami kekeliruan dalam menyelesaikan soal FPB dan KPK, yaitu ketika dihadapkan dengan soal FPB siswa menggunakan langkah-langkah penyelesaian soal KPK.

Berdasarkan latar belakang diatas, peneliti akan melakukan penelitian dengan judul "Analisis Minat Belajar Siswa pada Materi KPK dan FPB Menggunakan Pendekatan Saintifik berbantuan Aplikasi Visual Basic Excel (VBE)". 


\section{METODE}

Penelitian dilaksanakan di SDN Cibungur Batujajar. Populasi penelitian ini adalah siswa kelas IV SDN 1 Batujajar Kabupaten Bandung Barat periode 2019/2020. Sedangkan untuk sampel penelitian adalah kelas IV A dengan jumlah 29 siswa. Pemilihan subjek berdasarkan saran dari guru mata pelajaran. Teknik pengumpulan data diperoleh dari angket siswa berupa pernyataanpernyataan yang berhubungan dengan minat belajar siswa dalam mempelajari materi pokok bahasan KPK dan FPB. Prosedur dalam penelitian ini terdiri dari 3 tahapan yakni, tahap persiapan, tahap pelaksanaan dan tahap analisis. Pada tahapan persiapan dilakukan penyusunan instrumen penelitian. Instrumen yang digunakan dalam penelitian ini adalah soal non tes yang memuat 20 pernyataan yang terdiri dari pernyataan 10 positif dan 10 pernyataan negatife, beserta rubrik penilaiannya. Data dikatagorikan menggunakan batasan yang ditemukan oleh Arikunto (2008), batasan tersebut tercantum pada Tabel 1 berikut ini:

\section{Tabel 1.}

\section{Kriteria Penilaian Data}

\begin{tabular}{|c|c|}
\hline Presentase & Kriteria \\
\hline $81-100$ & Sangat baik \\
\hline $61-80$ & Baik \\
\hline $41-60$ & Cukup \\
\hline $21-40$ & Kurang \\
\hline $0-20$ & Sangat kurang \\
\hline
\end{tabular}

Diatas merupakan kriteria penilaian dan dibawah ini tabel 2 merupakan penilaian skala sikap minat belajar siswa :

\section{Tabel 2.}

Penilaian skala sikap Minat belajar

\begin{tabular}{|c|c|c|}
\hline Respon & Positif & Negatif \\
\hline Sangat Setuju (SS) & 4 & 1 \\
\hline Setuju (S) & 3 & 2 \\
\hline Tidak Setuju (TS) & 2 & 3 \\
\hline Sangat Tidak Setuju (STS) & 1 & 4 \\
\hline
\end{tabular}

Angket minat belajar siswa terdiri dari 20 pernyataan yaitu 10 pernyataan positif dan 10 pernyataan negatife. Angket yang diberikan berupa angket tertutup yang terdapat empat pilihan jawaban, yaitu sangat setuju (SS), setuju (S), tidak setuju (TS), dan sangat tidak setuju (STS) kepada 29 siswa SDN Cibungur Batujajar kelas IV A. Pengolahan dan analisis angket dilakukan melalui pembuatan tabulasi data dan menentukan presentase jawaban siswa berikut ini merupakan angket yang diberikan kepada siswa,sebagai berikut: 
Tabel 3.

Pernyataan angket minat belajar siswa

\begin{tabular}{|c|c|c|c|c|c|}
\hline \multirow{2}{*}{ No } & \multirow{2}{*}{ PERNYATAAN } & \multicolumn{4}{|c|}{ RESPON } \\
\hline & & SS & $\mathbf{S}$ & TS & STS \\
\hline \multicolumn{2}{|r|}{ Perasaan senang } & \multicolumn{4}{|c|}{ Skor : 309} \\
\hline 1 & $\begin{array}{l}\text { saya menyukai pembelajaran matematika menggunakan Ms.excel } \\
(+)\end{array}$ & & & & \\
\hline 2 & $\begin{array}{l}\text { saya merasa pembelajaran matematika kurang menyenangkan } \\
\text { menggunakan Ms.excel (-) }\end{array}$ & & & & \\
\hline 3 & $\begin{array}{l}\text { saya memahami pembelajaran matematika yang dijelaskan guru } \\
\text { dengan menggunakan Ms.excel (+) }\end{array}$ & & & & \\
\hline \multicolumn{2}{|c|}{ Ketertarikan Siswa } & \multicolumn{4}{|c|}{ Skor : 495} \\
\hline 4 & $\begin{array}{l}\text { saya kurang mengerti dengan materi matematika yang dijelaskan } \\
\text { guru menggunakan Ms.excel (-) }\end{array}$ & & & & \\
\hline 5 & $\begin{array}{l}\text { saya semangat mengikuti pembelajaran matematika bila } \\
\text { menggunakan Ms.excel (+) }\end{array}$ & & & & \\
\hline 6 & $\begin{array}{l}\text { pembelajaran matematika menggunakan Ms.excel membuat } \\
\text { saya bosan belajar (-) }\end{array}$ & & & & \\
\hline 7 & $\begin{array}{l}\text { ketika belajar menggunakan Ms.excel membuat saya kurang } \\
\text { fokus pada } \\
\text { materi yang dijelaskan oleh guru (-) }\end{array}$ & & & & \\
\hline 8 & $\begin{array}{l}\text { saya bersemangat menyimak materi matematika yang dijelaskan } \\
\text { guru menggunakan Ms.excel (+) }\end{array}$ & & & & \\
\hline \multicolumn{2}{|c|}{ Keterlibatan } & \multicolumn{4}{|c|}{ Skor : 371} \\
\hline 9 & $\begin{array}{l}\text { saya merasa terbebani karena tidak mengerti dengan materi } \\
\text { matematika } \\
\text { yang dijelaskan menggunakan Ms.excel (-) }\end{array}$ & & & & \\
\hline 10 & $\begin{array}{l}\text { selama pembelajaran matematika menggunakan Ms.excel } \\
\text { saya berani mengemukakan pendapat }(+)\end{array}$ & & & & \\
\hline 11 & $\begin{array}{l}\text { saya merasa malu ketika disuruh mengerjakan soal didepan } \\
\text { kelas menggunakan Ms.excel (-) }\end{array}$ & & & & \\
\hline 12 & $\begin{array}{l}\text { saya malas membuat catatan matematika yang sudah } \\
\text { diajarkan dengan Ms.excel (-) }\end{array}$ & & & & \\
\hline \multicolumn{2}{|r|}{ rajin belajar dan rajin mengerjakan tugas matematika } & \multicolumn{4}{|c|}{ Skor : 301} \\
\hline 13 & $\begin{array}{l}\text { saya bersemangat mengerjakan soal-soal matematika yang tidak } \\
\text { rutin dengan Ms Excel }(+)\end{array}$ & & & & \\
\hline 14 & $\begin{array}{l}\text { saya memilih sendiri mengerjakan tugas matematika dengan } \\
\text { Ms.Excel karena menyukainya }(+)\end{array}$ & & & & \\
\hline 15 & $\begin{array}{l}\text { saya enggan mengerjakan tugas matematika dengan Ms.excel } \\
\text { karena rumit (-) }\end{array}$ & & & & \\
\hline 16 & $\begin{array}{l}\text { saya memilih mengerjakan soal matematika dengan Ms. Excel } \\
\text { karena lebih sederhana }(+)\end{array}$ & & & & \\
\hline
\end{tabular}


Analisis Minat Belajar Siswa Pada Materi KPK dan FPB Menggunakan Pendekatan Saintifik Berbantuan Aplikasi

\begin{tabular}{|c|l|l|l|l|}
\hline \multicolumn{2}{|l|}{ tekun dan disiplin dalam belajar dan memiliki jadwal belajar } & Skor : 303 \\
\hline 17 & $\begin{array}{l}\text { saya tetap berusaha menyelesaikan soal matematika dengan Ms } \\
\text { Excel yang } \\
\text { sulit meskipun perlu waktu yang lama (+) }\end{array}$ & & & \\
\hline 18 & $\begin{array}{l}\text { menyelesaikan soal matematika dengan Ms excel memerlukan } \\
\text { waktu yang lama dan sulit membuat saya bosan (-) }\end{array}$ & & & \\
\hline 19 & $\begin{array}{l}\text { saya pengumpulan tugas matematika lebih awal karena } \\
\text { menggunakan Ms Excel (+) }\end{array}$ & $\begin{array}{l}\text { Saya terlambat mengumpulkan tugas karena mesulitan dalam } \\
\text { menggunakan Ms excel (-) }\end{array}$ & & \\
\hline
\end{tabular}

\section{HASIL}

Kegiatan yang dilakukan selama proses pembelajaran yaitu:

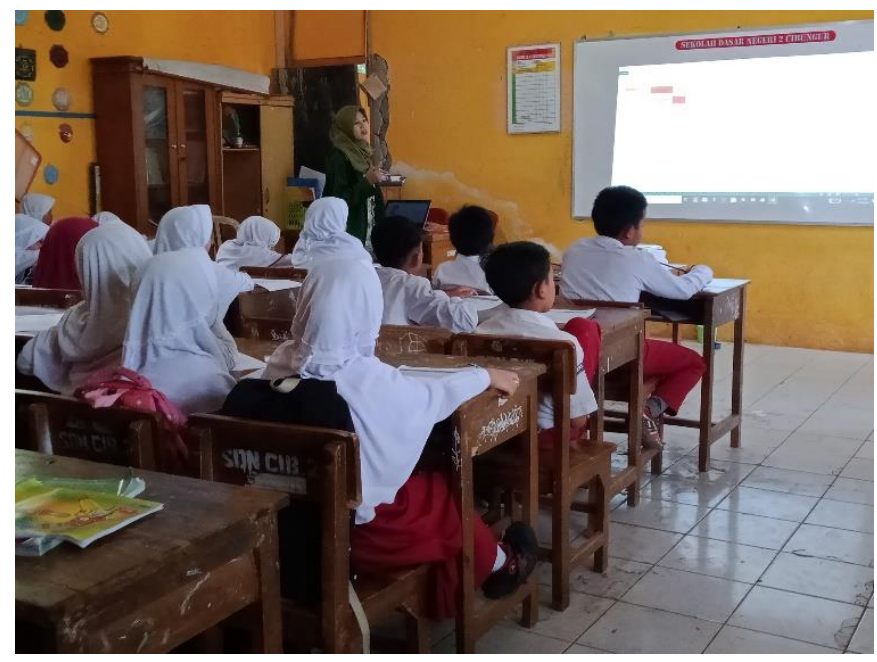

Gambar 1. Siswa Sedang Diberikan Materi dengan VBA Excel

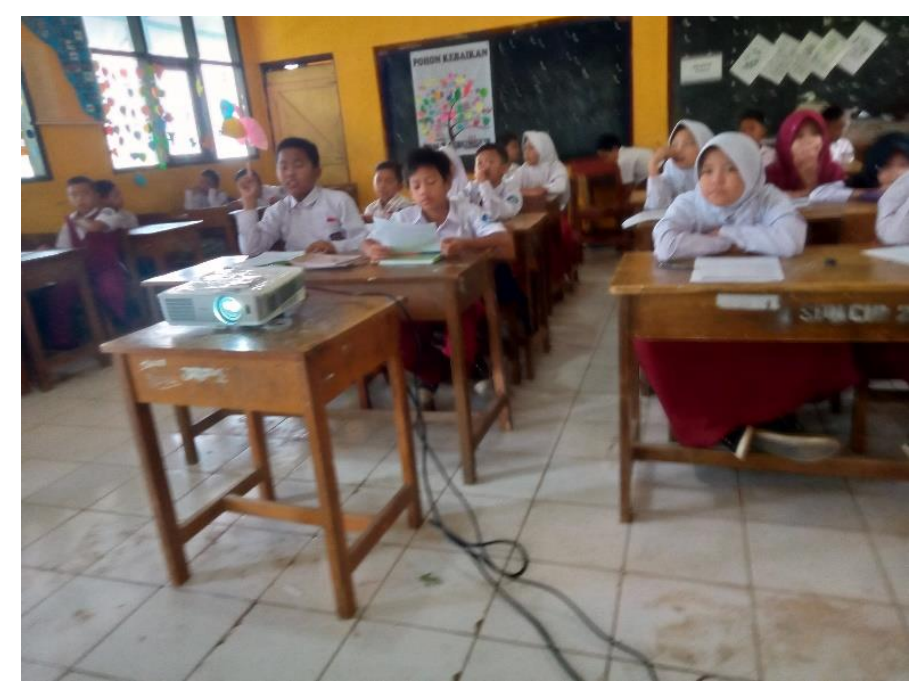

Gambar 2. Siswa Aktif dan Fokus Selama Proses Pembelajaran 


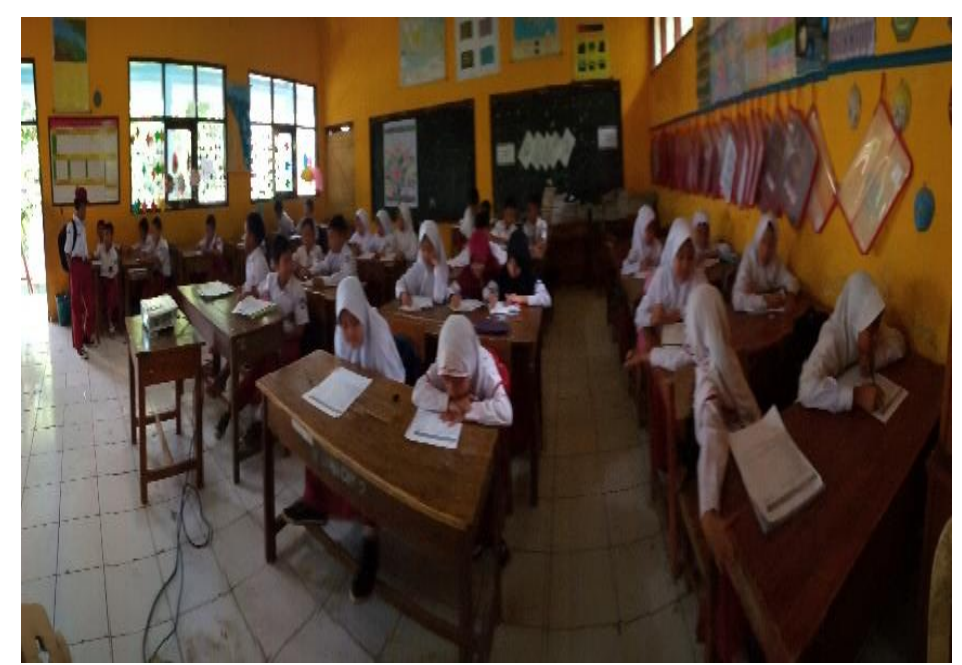

Gambar 3. Siswa mengerjakan soal KPK dan FPB secara mandiri

Berdasarkan hasil penelitian yang dilakukan pada siswa kelas IV di SDN Cibungur Batujajar peneliti melakukan pengolahan data dan diperoleh hasil berikut ini:

\section{Tabel 4.}

Persentase Skala Sikap Minat Belajar

\begin{tabular}{|c|c|c|c|c|c|c|}
\hline No & Indikator & $\begin{array}{c}\text { banyak } \\
\text { pernyataan }\end{array}$ & skor & mean & \multicolumn{2}{|c|}{ persentase } \\
\hline 1 & perasaan senang & 3 & 309 & 10.66 & $88.79 \%$ & sangat tinggi \\
\hline 2 & ketertarikan siswa & 5 & 495 & 17.07 & $85.34 \%$ & sangat tinggi \\
\hline 3 & keterlibatan siswa & 4 & 371 & 12.79 & $79.96 \%$ & tinggi \\
\hline 4 & $\begin{array}{c}\text { rajin belajar dan rajin } \\
\text { mengerjakan tugas } \\
\text { matematika }\end{array}$ & 3 & 301 & 10.38 & $86.49 \%$ & sangat tinggi \\
\hline 5 & $\begin{array}{c}\text { tekun dan disiplin dalam } \\
\text { belajar dan memiliki } \\
\text { jadwal belajar }\end{array}$ & 3 & 303 & 10.45 & $87.07 \%$ & sangat tinggi \\
\hline
\end{tabular}

Berdasarkan Tabel 4, menunjukan bahwa indikator perasaan senang memperoleh persentase rata-rata yaitu $88,79 \%$ dengan kategori sangat tinggi, indikator ketertarikan siswa memperoleh persentase rata-rata $85,34 \%$ dengan kategori sangat tinggi, indikator keterlibatan siswa memperoleh persentase rata-rata $79,96 \%$ dengan kategori tinggi, indikator rajin dalam belajar dan rajin dalam mengerjakan tugas matematika memperoleh persentase rata-rata $86,49 \%$ dengan kategori sangat tinggi, dan indikator tekun dan disiplin dalam belajar dan memiliki jadwal belajar memperoleh persentase ratarata $87,07 \%$ dengan kategori sangat tinggi.

Secara Grafis, Tabel 4 Dapat Disajikan Sebagai Diagram Yang Ditunjukkan Oleh Gambar 4. 


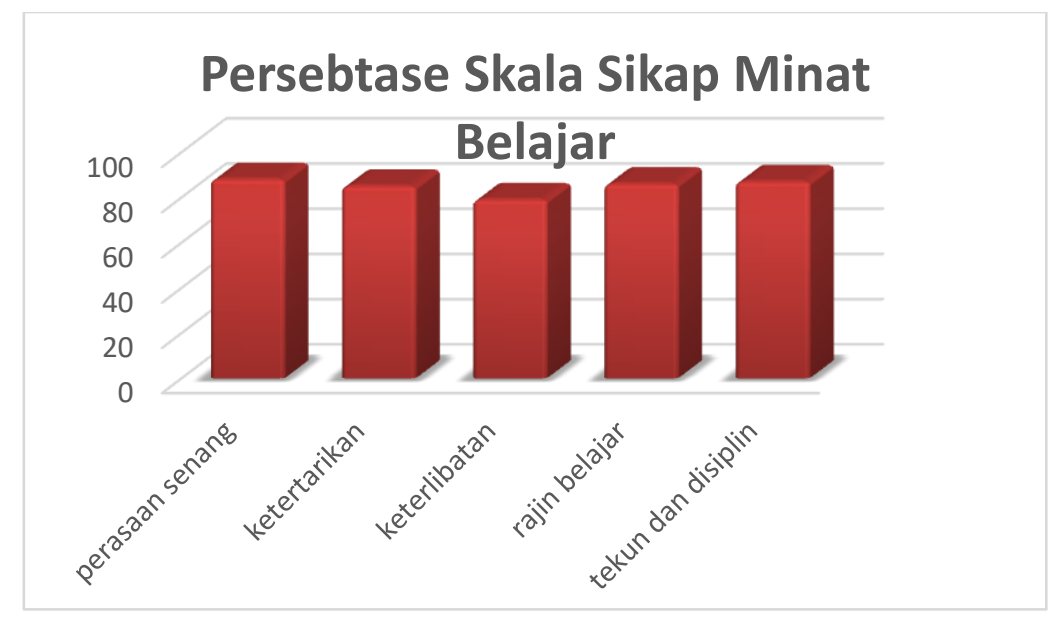

Gambar 4. Diagram Minat Belajar Matematika Siswa Menggunaan Visual Basic Application

Hasil pada penelitian ini menunjukan bahwa respon siswa dalam pembelajaran matematika menggukan aplikasi VBA itu sangat positif. Hal tersebut ditunjukan oleh persentase rata-rata yang masuk kategori sedang, tinggi dan sangat tinggi. Dengan kata lain penggunaan aplikasi VBA dapat meningkatkan minat siswa dalam belajar matematika.

\section{KESIMPULAN}

Berdasarkan hasil pengolahan data dari angket yang dijawab siswa kelas IV SDN Cibungur Batujajar, dapat disimpulkan bahwa pembelajaran matematika berbantuan media ICT VBA dapat meningkatkan minat belajar siswa. Sehingga dengan begitu, penggunaan media ICT VBA dapat menjadi salah satu alternatif untuk menjadikan pembelajaran lebih menarik dan menyenangkan.

\section{DAFTAR PUSTAKA}

Ambarwati, L. H., Setiawan, I., Akbar, P., \& Afrilianto, M. (2018). SISWA SMP DENGAN METODE PEMBELAJARAN AKTIF. 01(02), 297-308.

Andiyana, M. A., Maya, R., \& Hidayat, W. (2018). Analisis kemampuan berpikir kreatif matematis siswa smp pada materi bangun ruang. 1(3), 239-248. https://doi.org/10.22460/jpmi.v1i3.239248

Nurhasanah, S., \& Sobandi, A. (2016). Minat belajar sebagai determinan hasil belajar siswa. 1(1), $128-135$.

Nurhayati, L., \& Chotimah, S. (2020). Analisis Pengaruh Penggunaan Visual Basic Application Terhadap Minat Belajar Matematika Siswa SD pada Materi Bilangan Prima Analysis of interest in Learning Elementary School on Prime Numbers Assisted by Visual Basic Application. 10(April).

Rostika, D., Indonesia, U. P., \& Cibiru, K. (2019). Pemahaman Guru Tentang Pendekatan Saintifik 
Dan Implikasinya dalam Penerapan Pembelajaran di Sekolah Dasar. 11(1), Volume 11 Nomor 1. hal. 86-94. https://ejournal.upi.edu/index.php/eduhumaniora/article/view/14443 